\title{
Evaulation of Surgical Treatment of Fracture Capitullum (Review Report).
}

\author{
Dr. Sunil V Patil, Dr. P.B. Magdum, Dr. Vishwas Phadake, \\ MS , Mch.(Ortho),MBA (HR). Assoc Prof Bharati Vidyapeeth University Medical College \& Hospital, Sangli. \\ Prof Bharati Vidyapeeth University Medical College \& Hospital, Sangli. \\ Asst. Prof Bharati Vidyapeeth University Medical College \& Hospital, Sangli
}

\section{Introduction.-}

Fractures of the capitellum are rare. The complete capitellar fracture pattern was first described in the 19th century (1853) by doctors Hahn and Steinthal; the eponym for this fracture pattern includes their names. Later, doctors Kocher and Lorenz described an additional variation of this fracture pattern; a classification system includes their names.

Because of the rarity of capitellar fractures, controversies exist regarding the most appropriate treatment. The fracture fragment is intra-articular and requires treatment and reduction to reestablish normal elbow motion. Difficulty arises from the varying sizes of the fracture fragment and from the amount of suitable subchondral bone that is present to achieve stable fixation and to allow early elbow motion. Failure of adequate intervention may result in an incongruous joint, as well as in stiffness, instability, and chronic pain. ${ }^{1}$

Treatment modalities vary from conservative, in the form of closed reduction ${ }^{6,15}$ and immobilization, fragment excision to open reduction and internal fixation ${ }^{12}$ with $\mathrm{K}$ wires and $4 \mathrm{~mm}$ partially threaded cancellous screws or Herbert screws. ${ }^{9,18}$

Open reduction and stable internal fixation helps in early mobilization ${ }^{17}$, preventing stiffness of the elbow, and subsequent degenerative arthritis, as the articular congruity is maintained by anatomical reduction. Extension of the capitellar fracture well medially into the trochlea is reported and currently classified as the fourth type.

This is also described as the coronal shear fracture. The fragment is intra-articular, usually, without any soft tissue attachments. If not properly treated it results in malunion interfering with flexion of the elbow. The fragment has to be anatomically reduced and properly stabilized to prevent articular incongruity and late onset arthritis $^{2}$. A proper classification helps in pre-operative planning and execution of the surgical stabilization.

As early as 1935, Mazel described capitellum fracture as a layer of bone with a portion of trochlea attached to it. Capitellar fractures are classified into three types.

Type 1 (Hahn-Steinthal fracture) which consists of a large fragment of cancellous bone of the articular surface of capitellum and may include a portion of the trochlea, typically the lateral third;

Type 2 fracture (Kocher-Lorenz fracture) which is cartilaginous articular fracture of the capitellum and may include a small fragment of sub-chondral bone typically described as "uncapping" of the capitellum;

Type 3 (Broberg and Morrey), a comminuted capitellar fracture.

If the fracture extends to more than the lateral half of the trochlea it is considered a separate entity. Another fracture, described only in children, the "sleeve fracture," has also been reported.

As per AO classification, these will be classified as B3.1 (capitellar fractures), B3.2(trochlear) and B3.3 (capitellar and trochlear fractures).

- Bryan and Morrey classification ${ }^{7}$

- Type I: (Hahn-Steinthal fracture) $)^{24}$

- Complete fracture of capitellum

- Type II: (Kocher-Lorenz fracture)

○ Type III

- Superficial osteochondral fracture fragment

- $\quad$ McKee modification ${ }^{8,20}$

Comminuted

$\circ \quad$ Type IV

\section{Frequency}

- Coronal shear fracture including capitellum and trochlea ${ }^{25}$

Capitellar fractures account for $0.5-1 \%$ of all elbow fractures and $6 \%$ of all distal humeral fractures. ${ }^{4}$ Capitellar fractures are seen with greater frequency in females than in males; this is thought to be secondary to a greater carrying angle and an increased possibility of osteoporosis in females. In $20 \%$ of patients with capitellar 
fractures, radial head fractures also are found. ${ }^{5}$ Capitellar fractures do not occur in children younger than 10 years ${ }^{14}$. Because of the cartilaginous composition of the capitellum in children, a similar injury in a child would be a supracondylar or lateral condylar fracture. ${ }^{13}$

Fractures of the capitellum occur in the coronal plane. Separating the capitellum from the lateral column, capitellar factures are the result of shear forces from a fall onto the outstretched hand or of a fall directly onto the elbow. The capitellum is susceptible to shear forces because its center of rotation is $12-15 \mathrm{~mm}$ anterior to the humeral shaft. Capitellar fractures may be associated with radial head fractures and posterior dislocations of the elbow. ${ }^{5,21}$

\section{Material \& Methods:-}

Between 2007 and 2010 fourteen patients with 10 right sided type IV capetullar fracture \& 4 Left Sided fractures were treated in Bharati Hospital, Sangli. There were Eight males aged between 15 to 25 and Six women age gr from 25 to 38 years. A double arc sign in the lateral views of the X-rays of the elbow was seen in all the cases. Almost all cases operated with in 3-5 days of Trauma. When plain Xrays were misleading only those cases were subjected to CT scan examination.

Under tourniquet, using extended lateral (Kocher's) approach, The extensor origin was elevated in all cases subperiosteally including the origin of the extensor carpi radialis longus. The origin of the lateral collateral ligamentous complex from the lateral epicondyle was not disturbed. The exposure is extended distally between the anconeus and the extensor carpi ulnaris. Keeping the forearm pronated the extensor carpi ulnaris is elevated anteriorly. This allows the surgeon to reflect the soft tissues to keep the bone levers over the medial column. The extensive exposure aided in keeping a bone lever over the medial aspect of the distal humerus, thus helping in visualization of the entire articular surface of the distal humerus.

The fracture was reduced by checking the anterior articular surface, and held reduced with smooth $\mathrm{K}$ wires open reduction and internal fixation was done using $4 \mathrm{~mm}$ partially threaded $\mathrm{AO}$ cancellous screws $(\mathrm{n}=06)$ and $2.7 \mathrm{~mm} \mathrm{AO}$ screws $(\mathrm{n}=8)$ (Herbert Screws), under vision from posterior to anterior direction from the posterior aspect of lateral condyle of humerus avoiding articular penetration according to the fracture anatomy $\&$ ease of Fixation.

Plaster of Paris (POP) slab was given in all cases with elbow at 90 degrees of flexion and the forearm in neutral rotation. The patients were mobilized out of posterior slab after three weeks. Range of motion exercise was started under supervision of physiotherapist after six weeks. Clinical and radiological follow up was done at six weeks, three months, six months and one year. The elbows were tested for range of movements, and instability.

\section{Results:}

All the fractures united uneventfully. At the end of one year follow-up, twelve cases had excellent elbow function; implants were removed and there were no signs of AVN or arthritis. The other two cases had good elbow ROM at 11 months without AVN. The results were analysed by the Mayo Elbow Score.

\section{Mayo Elbow Performance Score}

\begin{tabular}{l|}
\hline Section $\mathbf{1}$ - Pain Intensity \\
\hline None \\
\hline Mild \\
\hline Moderate \\
\hline Severe \\
\hline Section $\mathbf{2}$ - Motion \\
\hline Arc of motion greater than 100 degrees \\
\hline Arc of motion between 50 and 100 degrees \\
\hline Arc of motion less than 50 degrees \\
\hline Section 3 - Stability \\
\hline Stable \\
\hline Moderate instability \\
\hline Grossly Unstable \\
\hline
\end{tabular}




\begin{tabular}{l} 
Section 4 - Function (Tick as many as able) \\
Can comb hair \\
\hline Can eat \\
\hline Can perform hygiene \\
\hline Can put on shirt \\
Can wear shoe \\
Interpreting the Mayo Elbow Performance Score
\end{tabular}

Interpreting the Mayo Elbow Performance Score

$\begin{array}{llllll}\text { Score greater than } 90 & \text { Excellent } & \text { Score 75-89 Good } & \text { Score 60-74 } & \text { Fair } & \begin{array}{l}\text { Score below } \\ 60\end{array}\end{array}$

\begin{tabular}{|c|c|c|c|c|c|c|c|}
\hline Sr No & Age/Sex & MOInjury & Xray & CTscan & Followup & Type Of Fixation & Functional Results. \\
\hline 1 & $27 / F$ & RTA & +++ & ----- & 10 mon & $4 \mathrm{~mm}$ CC Screws & Excellent \\
\hline 2 & $17 / \mathrm{M}$ & Playing & +++ & ----- & 12 mon & 2.7 Hbt Screw & Good. \\
\hline 3 & $22 / \mathrm{M}$ & Fall & +++ & ---- & $8 \mathrm{mon}$ & $4 \mathrm{~mm}$ CC Screws \& TBW & Good. \\
\hline 4 & $35 / F$ & RTA & +++ & --- & 12 mon & 2.7 Hbt Screw & Good \\
\hline 5 & $15 / \mathrm{M}$ & Direct Trauma & +++ & --- & 14 mon & 2.7 Hbt Screw & Excellent \\
\hline 6 & $22 / \mathrm{M}$ & Fall & +++ & +++ & 10 mon & $4 \mathrm{~mm}$ CC Screws & Fair \\
\hline 7 & $28 / \mathrm{M}$ & Direct Trauma & +++ & ---- & 09 mon & 2.7 Hbt Screw & Good. \\
\hline 8 & $33 / \mathrm{F}$ & RTA & +++ & +++ & 15 mon & 2.7 Hbt Screw & Excellent \\
\hline 9 & $20 / \mathrm{M}$ & Fall & +++ & ----- & 12 mon & $4 \mathrm{~mm}$ CC Screws \& TBW & Good. \\
\hline 10 & $16 / \mathrm{M}$ & Direct Trauma & +++ & ---- & 08 mon & 2.7 Hbt Screw & Excellent \\
\hline 11 & $34 / F$ & Sword trauma & +++ & ---- & 10 mon & $4 \mathrm{~mm}$ CC Screws & Fair \\
\hline 12 & $28 / F$ & Fall & +++ & ---- & 12 mon & 2.7 Hbt Screw & Good. \\
\hline 13 & $20 / F$ & Direct Trauma & +++ & ---- & 14 mon & 2.7 Hbt Screw & Good. \\
\hline 14 & $24 / \mathrm{M}$ & RTA & +++ & +++ & 09 mon & $4 \mathrm{~mm}$ CC Screws \& TBW & Fair \\
\hline
\end{tabular}
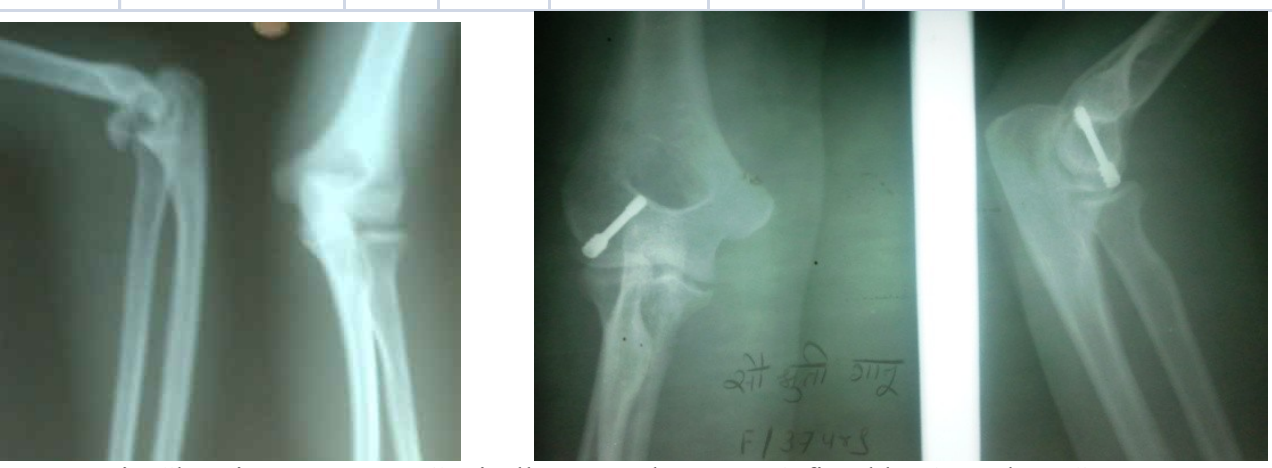

Fig Showing Fracture Capitullum Mckee Type3 fixed by 1 Herbert Screw.

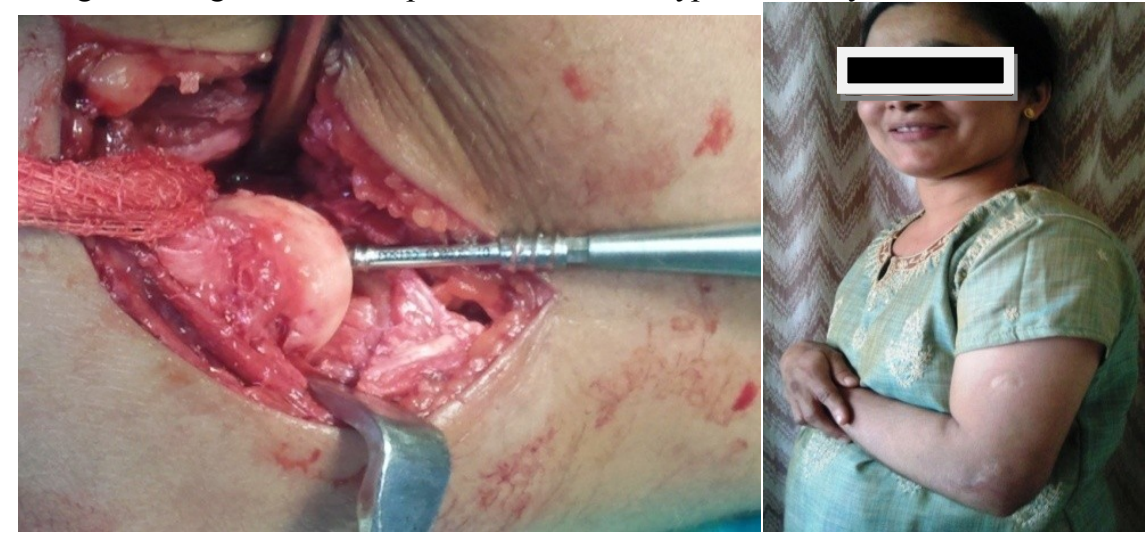


Fig Showing fracture Capitullum being reduced \& Fixed by AP Herbert Screw.\& Excellent Results.

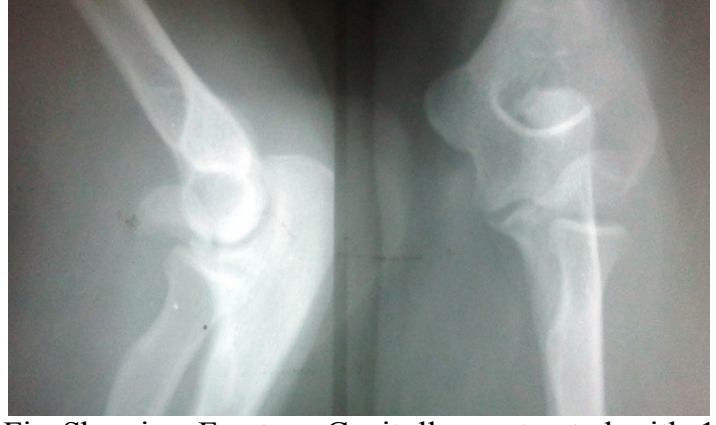

Fig Showing Fracture Capitullum after 4 weeks.

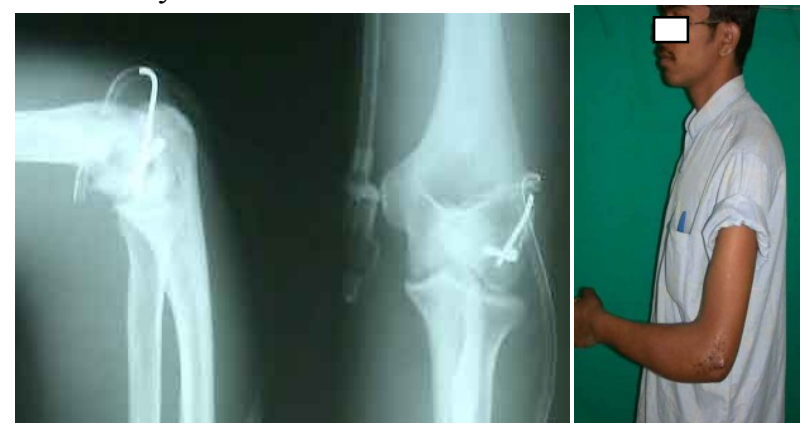

\& Threaded K-wire which was removed
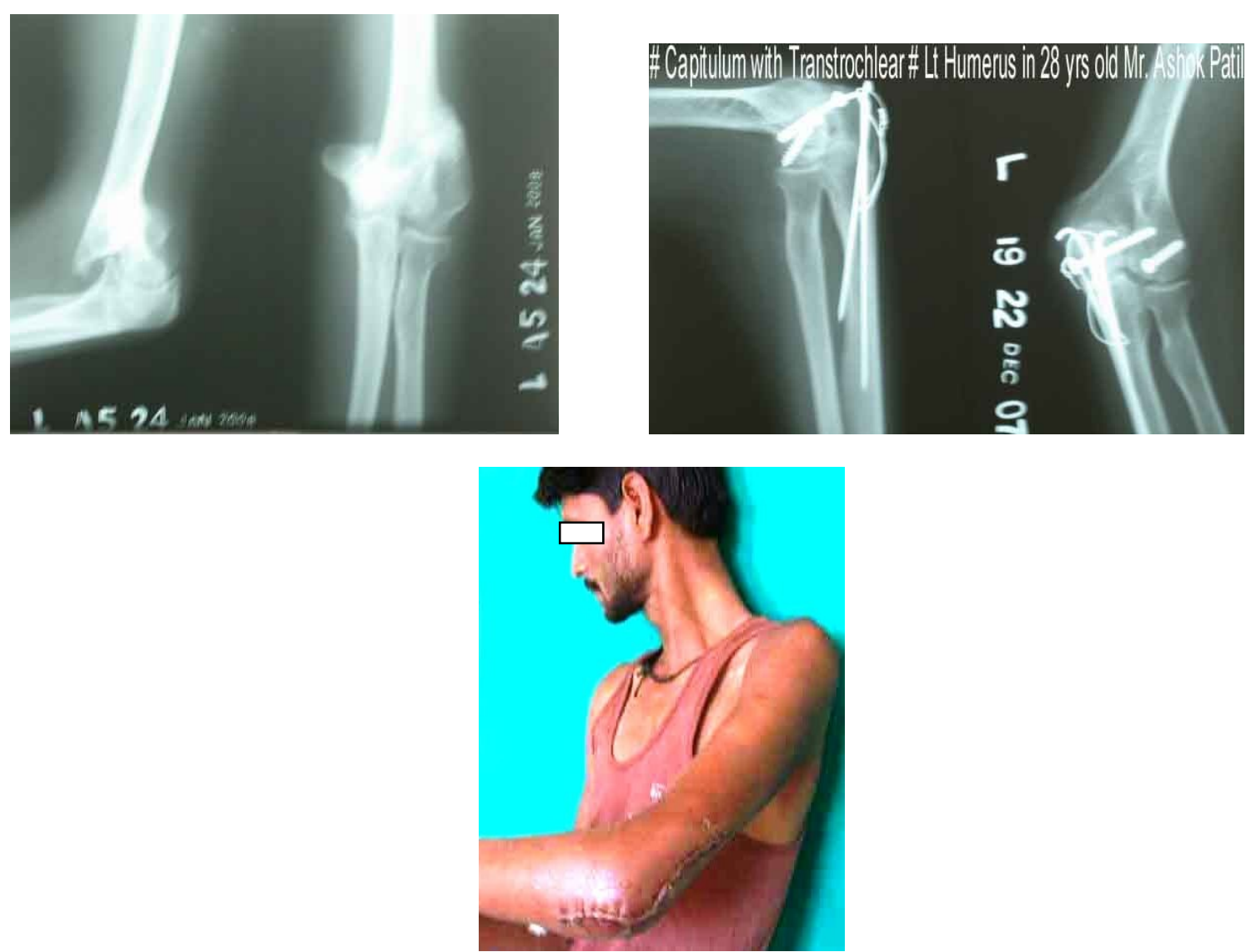

Fig showing T-Y elbow Fracture variant across the Capitullum.Treated by TBW for Olecranon 2 Herbert screws for the Fracture Capitullum.
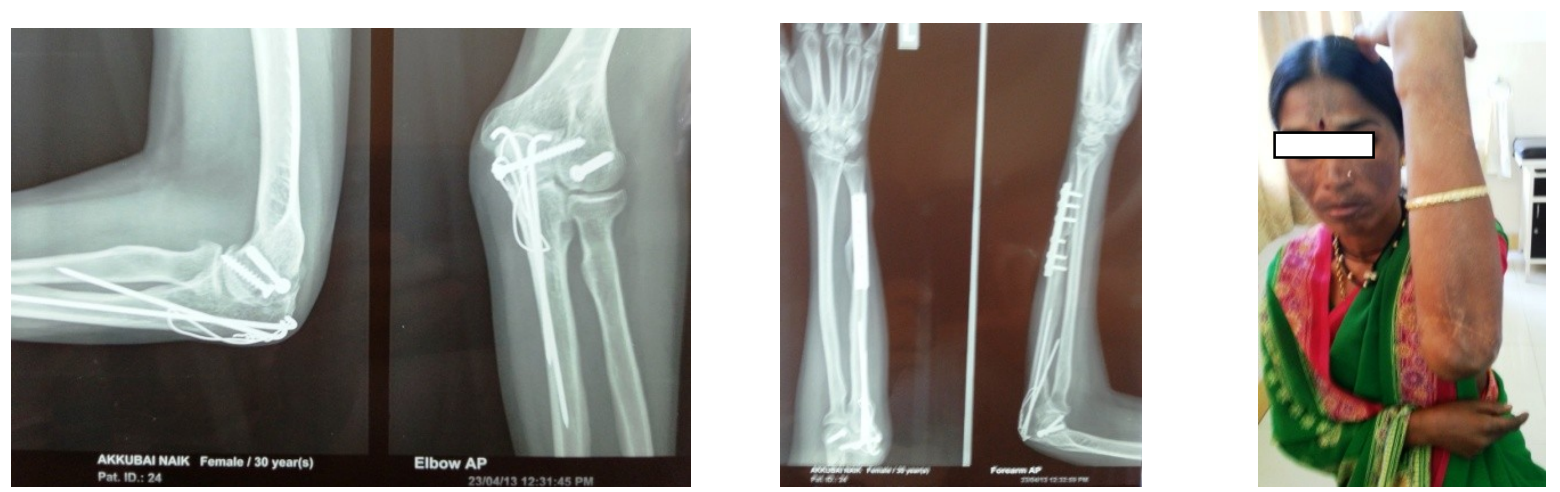

Fig Showing Post Traumatic (Sword Injury) across the Capitullum \& Olecranon \& Ulnar Fracture Distal Third. 

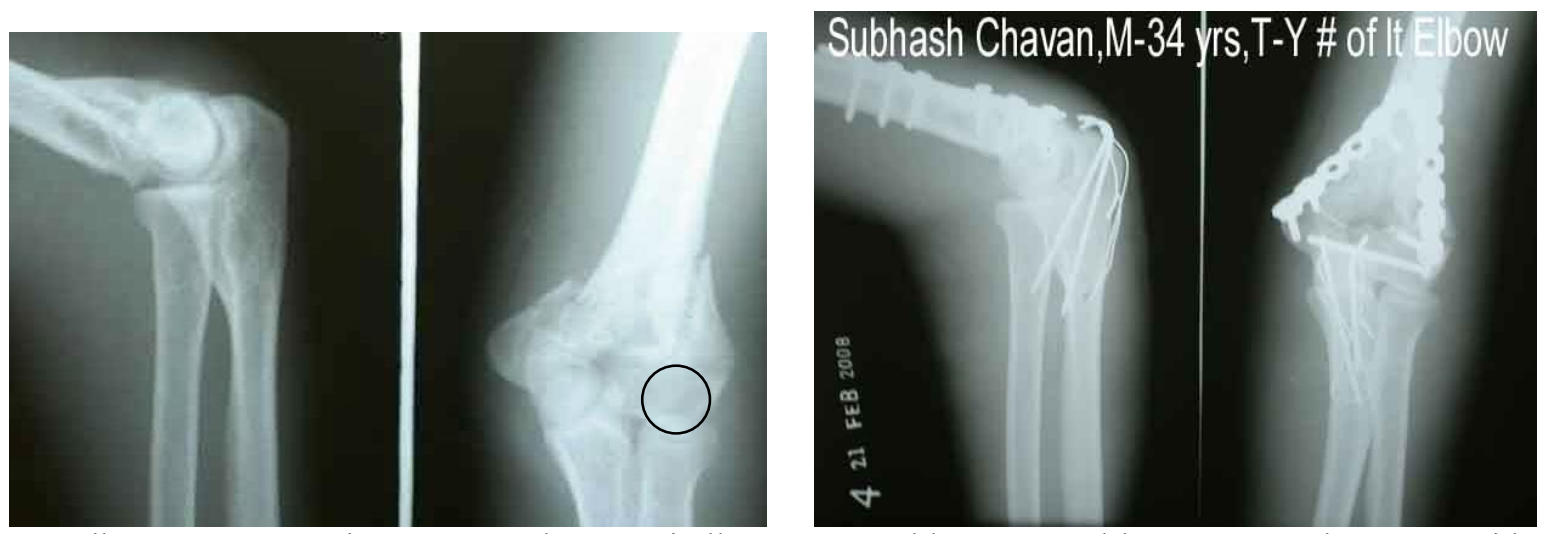

T-Y elbow Fracture variant across the Capitullum \& Trochlea. Treated by Trans Olecranon with 1 Cancellous screw for the Fracture Capitullum.\& 2 lateral Pillar Plates for I/A Fracture of distal Humerus. With Good Results. But With loss of terminal $10^{\circ}$ Extension.
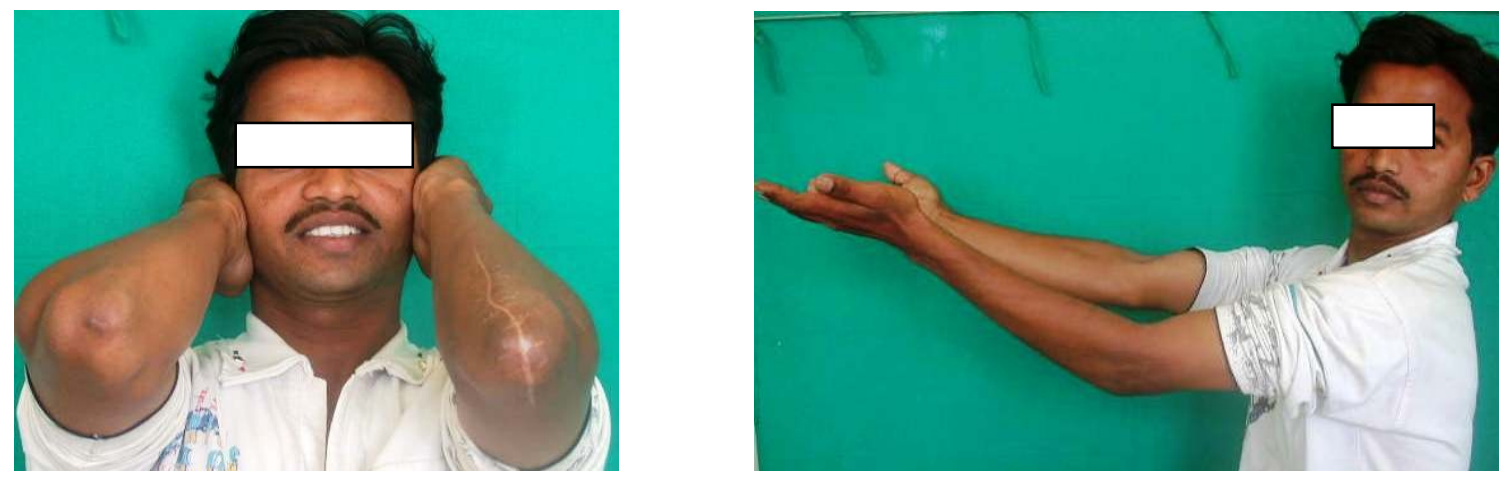

\section{Discussion:-}

Capitellum fractures are rare injuries that occur in adolescents over the age of 12 years.

Though, reportedly, more common in females, with a male to female ratio of 1:4, 8 of the 14 cases in this series were males. Mechanism of injury is usually a fall on the out-stretched hand, the radius imparting a shearing force on the capitellum. Maximum force transmission through the radial head ${ }^{21}$ to the capitellum occurs at zero to thirty degrees of elbow flexion. ${ }^{20}$

Proper visualization of the capitellar fragment is sometimes not possible in the routine views of the elbow and a radial head- capitellum view may help in better delineation of the fracture personality. Properly positioned lateral view is essential for diagnosis, with the fracture easily missed if the projection is slightly oblique as per Fowles and Kassab. ${ }^{15}$

A comparative view of the opposite elbow or CT scan will help in diagnosis. A properly taken lateral view usually shows anterior and superior migration of the capitellar fragment. Characteristic finding in the lateral X-ray is the "double-arc sign" because of the sub-chondral bone of the capitellum and lateral part of trochlea. The sub-chondral bone of the trochlea creates the double arc and when this sign is present it signifies that a part of the trochlea is also involved. ${ }^{3}$

Radiological diagnosis is difficult in a child because the capitellum is not fully ossified and fused before the age of 9-10 years. Other authors have suggested an oblique radiograph to detect this injury. In case of difficulty, in interpreting the radiographs.CT is advocated.

Fractures are often missed in the emergency room setting as the outline of the distal end of the humerus is intact. A CT scan delineates the fracture extent more clearly and helps the surgeon plan the approach, since, if the fragment is displaced on the medial side, another medial approach may be needed for reduction.

Treatment of type 2 and 3 capitullum fractures can be either conservative or excision of the fragments. Ochner reported, in 1996, successful outcome of closed reduction of coronal fractures of the capitellum in nine cases with long term follow-up.

In none of our cases closed reduction was attempted even before open reduction. Closed reduction of the fracture can lead to early arthritis, loss of motion of the elbow or instability of the elbow as it is usually a non anatomical reduction. ${ }^{10}$

Excision of the fragment can lead to instability of the elbow. Excision to prevent avascular necrosis is suggested by few authors. Fragment excision due to fear of avascular necrosis or redisplacement can lead to 
radio-humeral osteoarthritis and instability of the elbow. Alvarez ${ }^{11}$ advocated excision of the fragment in 10 out of 14 cases.

Approaches described include lateral approach (Modified Kocher approach), 'posterior approach with olecranon osteotomy ${ }^{19}$. Sano advocates olecranon osteotomy approach for proper visualization of the trochlea, but in the present series by retracting the medial structures with a bone lever the entire medial aspect of the trochlea could be visualized. The authors found the olecranon osteotomy approach useful if the trochlea also need to be fixed. Screws inserted from posterior to the anterior (PA) direction have more bio-mechanical stability than antero-posterior screws and this prevents damage to the articular cartilage.

Moreover, purchase of screw threads in the sub-chondral bone is more in PA directed screws, and splintering of the sub-chondral bone due to countersinking is less. Lateral collateral ligament has to be preserved during the procedure.

Various internal fixation methods have been described, including $\mathrm{K}$ wires, $4 \mathrm{~mm}$ cancellous screws, Herbert screws and absorbable polyglycide pins. There are also reports of plate fixation of the fracture. Kirschner wires do not provide enough stability for mobilization before fracture healing and also damage the articular cartilage. The better functional outcome of operative fixation has been documented.

Headless screws can have problems if the patients develop AVN or chondrolysis, because erosion of the radial head is a possibility due to exposed implants. This problem is avoided by the $4 \mathrm{~mm}$ partially threaded screws, which could be easily removed through stab incisions. Reports of avascular necrosis of the capitellum are very rare.

Grantham reported an elbow assessment based on stability, pain and range of movements, which is easy to follow.

Excellent - normal stability, no pain and full range of movements,

Good - less than 10 degree of instability, mild pain and less than 40 degree restriction of range of movements,

Fair -10-15 degree of instability, moderate pain or 40-60 degree of loss of range of motion,

Poor - 15 degree or greater instability, troublesome pain, or 60 degree or more of loss of range of motion.

Articular damage is thought to be the reason for residual extensor lag in spite of anatomical reduction and early mobilization.

\section{Conclusion:-}

Type 4 Isolated capitellar fractures ${ }^{23}$ are less due to rarity of the injury. The importance of noting double arc sign in lateral view X-rays of the elbow and CT scan evaluation preoperatively is emphasized. The results of fixation with cannulated AO screws through extended lateral Kocher's approach has given good results. Good Anatomical Reduction, Rigid Internal Fixation \& Early mobilization gives excellent results. This report is presented though there is no long term follow-up \& sample size is also small to document posttraumatic arthritis \& AVN

\section{References}

[1]. Ashwood N, Verma M, Hamlet M, Garlapati A, Fogg Q. Transarticular shear fractures of the distal humerus. J Shoulder Elbow Surg. Jan-Feb 2010;19(1):46-52. [Medline]

[2]. Ruchelsman DE, Tejwani NC, Kwon YW, Egol KA. Open reduction and internal fixation of capitellar fractures with headless screws. Surgical technique. J Bone Joint Surg Am. Mar 1 2009;91 Suppl 2 Pt 1:38-49. [Medline].

[3]. Guitton TG, Doornberg JN, Raaymakers EL, Ring D, Kloen P. Fractures of the capitellum and trochlea. J Bone Joint Surg Am. Feb 2009;91(2):390-7. [Medline].

[4]. Ruchelsman DE, Tejwani NC, Kwon YW, Egol KA. Coronal plane partial articular fractures of the distal humerus: current concepts in management. J Am Acad Orthop Surg. Dec 2008;16(12):716-28. [Medline].

[5]. Nalbantoglu U, Gereli A, Kocaoglu B, Aktas S, Turkmen M. Capitellar cartilage injuries concomitant with radial head fractures. J Hand Surg Am. Nov 2008;33(9):1602-7. [Medline].

[6]. Ochner RS, Bloom H, Palumbo RC, et al. Closed reduction of coronal fractures of the capitellum. J Trauma. Feb 1996;40(2):199203. [Medline].

[7]. Bryan RS, Morrey BF. Fractures of the distal humerus. In: Morrey BF, ed. The Elbow and Its Disorders. Philadelphia, Pa: WB Saunders; 1985:302-39.

[8]. McKee MD, Jupiter JB, Bamberger HB. Coronal shear fractures of the distal end of the humerus. J Bone Joint Surg Am. Jan 1996;78(1):49-54. [Medline].

[9]. Ruchelsman DE, Tejwani NC, Kwon YW, Egol KA. Open reduction and internal fixation of capitellar fractures with headless screws. J Bone Joint Surg Am. Jun 2008;90(6):1321-9. [Medline].

[10]. . Brouwer KM, Jupiter JB, Ring D. Nonunion of operatively treated capitellum and trochlear fractures. J Hand [11]. Alvarez E, Patel MR, Nimberg G, Pearlman HS. Fractures of the capitulum humeri. J Bone Joint Surg Am. 1975;57:10936.[PubMed]

[12]. Elkowitz SJ, Polatsch DB, Egol KA, Kummer FJ, Koval KJ. Capitellum fractures: A fixation methods. J Orthop Trauma. 2002;16:503-6.[PubMed]

[13]. De Boeck H, Pouliart N. Fractures of the capitellum humeri in adolescents. Int Orthop

[14]. Pradhan BB, Bhasin D, Krom W. Capitellar fracture in a child: The value of an oblique Surg Am. 2005;87:635-8.[PubMed]

[15]. Ochner RS, Bloom H, Palumbo RC, Coyle MP. Closed reduction of coronal fractures of the J Jrauma. 1996;40:199-203.[PubMed]

biomechanical evaluation of three

$2000 ; 24: 246-8$

radiograph: A case report. J Bone Joint 
[16]. Fowles JV, Kassab MT. Fracture of the capitulum humeri: Treatment by excision. J Bone Joint 8.[PubMed]

[17]. Dubberley JH, Faber KJ, Macdermid JC, Patterson SD, King GJ. Outcome after open capitellar and trochlear fractures. J Bone Joint Surg Am. 2006;88:46-54.[PubMed]

[18]. Lambert SM, Pike J, Railton GT. Fractures of the humeral capitellum: Herbert screw reduction and internal fixation of 1994;39:321-3.[PubMed]

[19]. Ring D, Jupiter JB, Gulotta L. Articular fractures of the distal part of the humerus. J Bone Joint Surg Am. 2003;85:2328.[PubMed]

[20]. McKee MD, Jupiter JB, Bamberger HB. Coronal shear fractures of the distal end of the 1996;78:49-54.[PubMed]

[21]. Morrey BF, An KN, Stormont TJ. Force transmission through the radial head. J Bone Joint Surg Am. 1988;70:250-6.[PubMed]

[22]. Greenspan A, Norman A, Rosen H. Radial head-Capitellum view in elbow trauma: Clinical radiographic-anatomic correlation. AJR Am J Roentgenol. 1984;143:355-9 [PubMed]

[23]. Grantham SA, Norris TR, Bush DC. Isolated fracture of the humeral capitellum. Clin Orthop 9.[PubMed]

[24]. Pogliacomi F, Concari G, Vaienti E. Hahn-Steinthal fracture: Report of two cases. Acta Biomed. 2005;76:178-84.[PubMed]

[25]. Mehdian H, McKee MD. Fractures of the capitellum and trochlea. Orthop Clin North Am. 2000;31:115-27.[PubMed] 